\title{
A poética apurada de Manucure de Mário de Sá-Carneiro
}

Mário de Sá-Carneiro's Manucure refined poetics

Resumo: Este artigo propõe uma leitura de Manucure de Mário de Sá-Carneiro conforme vários estilos literários representados na obra. São destacadas as "técnicas" do cubismo literário, os princípios do futurismo e os elementos do interseccionismo - fruto do modernismo português.

Palavras-chaves: Mário de Sá-Carneiro, Manucure, interseccionismo, futurismo

Abstract: The aim of this paper is to read Manucure by Mário de Sá-Carneiro according to various literary stiles represented in the poem. The Literary Cubism techniques, the Futurism principles and the elements of the stile named Intercessionism, the product of the Portuguese Modernism are detached.

Keywords: Mário de Sá-Carneiro, Manucure, Interseccionism, Futurism

* Doutora em Literatura Portuguesa pela Universidade Estatal de São Petersburgo, Federação Russa. 
poema Manucure de Mário de Sá-Carneiro foi publicado pela primeira vez em junho de 1915 no segundo número da revista lisboeta Orpheu. Cerca de um ano depois, o jovem mas já conhecido poeta suicidou-se, aos 25 anos de idade, e, desde então, sua obra foi por décadas negligenciada. Só nos anos 1950 surgiram os primeiros estudos sobre a lírica de Sá-Carneiro, mas voltados apenas para duas obras, Dispersão (1914) e Indícios de oiro (1935), deixando Manucure injustamente de lado. Naquela época, as vanguardas ainda não contavam com uma acepção adequada, nem com uma repercussão significativa entre críticos e leitores. Além disso, a novidade formal de Manucure, o tom otimista, destoava visivelmente da típica melancolia do autor achada em seus outros trabalhos em prosa e poesia. Ao tratar de Manucure, os críticos compartilhavam da ideia de Fernando Pessoa de que o poema fora escrito "com intenção de blague".

Gilberto Mendonça Teles, em Vanguarda europeia e modernismo brasileiro, já analisa Manucure ao lado de Ode triunfal e Ultimatum, de Álvaro de Campos, e de Manifesto anti-Dantas e Ultimatum futurista, de José de Almada-Negreiros, marcos do vanguardismo português. Visto como um manifesto, o poema de Sá-Carneiro é equiparado por Mendonça Teles com obras do quilate de Correspondências (Baudelaire); Futurismo (Marinetti); Bofetada no gosto público (irmãos Burliúk, Maiakóvski, Khlébnikov e Kruchónykh) e O Surrealismo (André Breton).

Manucure é o único exemplo de expressão vanguardista entre as obras de Sá-Carneiro, mas, ao longo deste não muito extenso poema, é possível identificar traços gerais do autor. Assim, encontra-se tanto sua preferência pelo espaço aéreo, no qual imagens flutuam, como a falta de confiança em suas próprias forças; além do apelo sensorial e da busca da Beleza - o leitmotiv de sua criação.

O título do poema já é em si intrigante. O processo de embelezamento das unhas é impulso direto para o desenvolvimento da ação, descrito pelo autor através de percepções subjetivas. Sá-Carneiro de fato era conhecedor do assunto: "Seu grande orgulho foram sempre as mãos que fazia tratar em manicures, então raras em Lisboa", recorda Rogério Perez, um de seus amigos do Liceu (MARTINS, 1994, p. 21). Para um poeta que está em busca da Beleza, embelezar as unhas é uma forma de realizar este ideal e, ao mesmo tempo, de gerar inúmeras sensações percetíveis pelo tato. Em carta a Fernando Pessoa de 21 de janeiro de 1913, Mário de Sá-Carneiro escreve: "Ora, enquanto o ouvido, o olhar, o paladar e o olfacto apenas existem cada um localizado no seu órgão, um sentido há que, concentrado nas mãos, vive entretanto em todo o nosso corpo - o tacto. 
Tirar todo o partido deste sentido eis o segredo principal do grande esteta" (SÁ-CARNEIRO, 2003, p. 35).

O tato, como uma sensibilidade distribuída em toda a superfície do corpo, está ligado aqui à perceção tátil de objetos distribuídos no espaço, isto é, no mundo real e mais, da do mesmo espaço. Essa ideia corresponde a anseios de poetas e pintores do início do século XX. Do círculo de Picasso, por exemplo, fez parte o matemático Maurice Princé, que relatou aos pintores as teorias de Henri Poincaré (Espaço e hipótese, 1902) da representação do espaço tátil e móvel, isto é, do espaço em relação à perceção sensorial ou em movimento. Portanto, a palavra "manucure" do título do poema pode ser interpretada como um símbolo da sensação tátil ou da perceção do mundo em sua essência.

Manucure é uma obra "de câmara" pois dotada das três unidades do esquema clássico: espaço (café), tempo (manhã) e ação, que, se se desenvolve na imaginação ascensional do poeta e se desenrola sucessivamente, não contradiz a conceção de "arte nova", transmitindo dinamismo e movimento.

Pela manhã, num café, o poeta, enquanto cuida de suas unhas (acentuando o lado sensorial e emocional), mergulha em diferentes influências do ambiente: no aspeto das mesas e das chávenas, no reflexo dos espelhos, nos jogos de luz das vitrines, em fragmentos de conversas, no estrondo das caixas, nas manchetes de jornais.

Em sua imaginação, as mesas e cadeiras do café encurvam-se e entrelaçam-se em combinações geométricas singulares, descritas pelo poeta, em diversos planos, por meio de inesperadas formações de luzes e sons, fazendo com que o leitor entre no centro da composição e sinta quase que fisicamente os movimentos dos objetos no espaço: "Mil cores no Ar, mil vibrações latejantes, / Brumosos planos desviados / Abatendo flechas, listas volúveis, discos flexíveis..." (SÁ-CARNEIRO, 1996, p.56).

As visões refratam-se nos espelhos, os objetos enxameiam o ar, formando uma espécie de mosaico. Os dizeres dos caixotes e dos embrulhos amontoados nas estações formam uma névoa variegada na qual se entrelaçam os arcos dos estribos, o contorno dos bancos, a cabeça dos pregos:

- Olha as mesas... Eia! Eia!

Lá vão todas no $\mathrm{Ar}$ às cabriolas,

Em séries instantâneas de quadrados 
Ali - mas já, mais longe, em losangos desviados...

E entregolfam-se as filas indestrinçavelmente,

E misturam-se às mesas as insinuações berrantes

Das bancadas de veludo vermelho

Que, ladeando-o, correm todo o Café... (ibidem, p 59.).

Logo do início do poema, o leitor pode sentir nos quadros criados reflexos do cubismo pictórico: fundo alusivo, desfiguração das proporções, achatamento das superfícies, preferência pelo preto, azul, vermelho e verde (os tons principais da escola cubista), fragmentação de objetos, angulosidade das formas, preservando-se, contudo, a ideia do objeto representado. Tais deformações seguem a lógica interna da composição, de maneira que as linhas, nas palavras de Picasso, "estendam-se uma a outra", ganhando vida própria:

E, mais alto, em planos oblíquos,

Simbolismos aéreos de heráldicas ténues

Deslumbram os xadrezes dos fundos de palhinha

Das cadeiras que, estremunhadas em seu sono horizontal,

Vá lá, se erguem também na sarabanda...

... E a que mágicas, em verdade, tudo baldeado

Pelo grande fluido insidioso,

Se volve, de grotesco - célere... (ibidem, p. 58-59).

Os interiores do café da estação refletem-se e refratam-se não só na imaginação do poeta, mas também nos espelhos (objeto caro à estética cubista): "nos rebentados espelhos do cubismo", diz Picasso, são importantes as ruturas e as convergências. Os objetos volumosos são acomodados no centro do quadro e neles se comprimem os outros elementos.

Todos esses procedimentos são percetíveis nos cem primeiros versos de $\mathrm{Ma}$ nucure. Pode-se dizer que nessa parte do poema Sá-Carneiro, um conhecedor da poesia inovadora de Apollinaire e de sua apologia à arte nova, utiliza o próprio código do cubismo analítico. Em missiva a Fernando Pessoa de 10 de março 
de 1913, o poeta escreve: "No entanto, confesso-lhe, meu caro Pessoa, que sem estar doido, eu acredito no cubismo" (SÁ-CARNEIRO, 2003, p. 57).

Sem interregno, o poeta intensifica as sensações: seus olhos "ungidos de Novo" "Não param de fremir, de sorver [...] toda essa Beleza-sem-Suporte [...]". Além disso, novos traços são acrescentados às imagens. A poeira multicolor enche o espaço, o poeta sente que nele cresce a tensão do Presente, o sol refratado na vitrine explode em "tintas em fantasia". O poeta olha para a mesa e vê: "... chávena banal de porcelana... / Ah, essa esgota-se em curvas gregas de ânfora, / Ascende num vértice de espiras / Que o seu rebordo frisado a ouro emite..." (SÁ-CARNEIRO, 1996, p. 59-60).

As linhas dos objetos circunvizinhos estreitam-se e arqueiam-se e as cores atingem a máxima intensidade. Como se espelhassem ao mesmo tempo as buscas artísticas do cubismo e as ideias de Apollinaire, Mário de Sá-Carneiro representa os objetos que o rodeiam em turbilhão, mas no estilo órfico, ou seja, no cubismo órfico, com objetos encurvados, quase esféricos, e atenção especial ao jogo de cores. Como o próprio Pessoa diz a Sá-Carneiro: “[...] o seu sentido da cor é dos mais intensos entre os homens de letras" (D’ALGE, 2006, p. 85).

Dessa maneira, toda a primeira parte de Manucure é o exemplo máximo da ideia polêmica de cubismo literário. ${ }^{1}$ Sá-Carneiro mostra formas esmeradas de interação da poesia com a pintura, da linguagem verbal com a imagética.

$\mathrm{Na}$ derradeira pincelada desta parte, o poeta dá uma magistral deixa teatral: "APOTEOSE.", isto é, no meio do poema, faz-se uma pausa prolongada.

Logo nos primeiros versos depois de "APOTEOSE. ${ }^{2}$ ", ele nos lembra que todos esses quadros, pintados com palavras e imaginação, cheios de dinamismo, não

\footnotetext{
1 Entre os críticos, pesquisadores e filósofos, não há opinião unânime sobre o cubismo literário. Os que o consideram um estilo independente encontram traços "cubistas" em textos de G. Apollinaire, BI. Cendrars, M. Jacob. Em carta a Fernando Pessoa de 10 de dezembro de 1912, logo ao chegar a Paris, Sá-Carneiro observa: "Dos artistas de hoje, a par do Parreira, apenas tem culto [Santa-Rita] por um literato cubista, Max Jacob, que ninguém conhece e publicou dois livros em tiragens de cem exemplares ... aliás cada volume custa $65 \mathrm{frs}$. Mas é genial!... porque é cubista..." (SÁ-CARNEIRO, 2003, p. 21).

2 Depois de sua publicação em 1946, o poema foi dividido em duas partes, publicadas durante muito tempo como obras independentes: Manucure e Apoteose. É evidente que tal organização causou polêmica. Sobre a querela, vale destacar cinco itens. 1 . O poema foi publicado em vida do autor, portanto, seria oportuno usar essa versão como base. Além disso, existe uma edição facsimilar de Orpheu 2, incluindo Manucure. 2. Nas cartas de Sá-Carneiro a Pessoa não há menção a qualquer divisão da obra. 3. Um ano antes da publicação de Manucure, Sá-Carneiro já tinha escrito
} 
ocorrem no silêncio ou num espaço insonoro. Por isso, nos cinquenta versos seguintes as imagens completam-se por "ondas acústicas". Assim, podemos caracterizar esse trecho do poema de audiovisual, que, com o enriquecimento do caráter imagético pelo sonoro, leva à realização de maior efeito de impressões: "Era o que faltava na paisagem... / As ondas acústicas ainda mais a subtilizam...".

Ao lado, ouve-se o toque do telefone: que "Laivos sonoros!". Uma voz dita um número, e cravam-se no ar algarismos sincronizados. Um garçom deixa cair uma bandeja, e o poeta vê ondas prateadas estenderem-se. As ondas acústicas unem-se a imagens, criando sinestesias requintadas, recurso favorito do poeta: "Que loiras oscilações se ri a boca da jogadora...", "Zurzem-se planos a meus ouvidos...".

À parte, o autor concentra-se na "ascensão da beleza numérica", colocando os algarismos e sinais aritméticos em ordem estética: ora como uma espécie de onda de rádio, ora imitando as ondas do mar - pouco antes de Manucure, cabos telegráficos foram passados pelo fundo do oceano Atlântico. E o poeta conclui sua "fórmula" com o sinal matemático do infinito $(\infty)$, que simboliza tanto a infinidade do espaço quanto a comunicação sem limites. Ao mesmo tempo, a disposição dos algarismos lembra, graficamente, a pauta musical, pois ocupa cinco linhas com cinco cifras à esquerda, dispostas de baixo para cima (SÁ-CARNEIRO, 1996, p. 61):

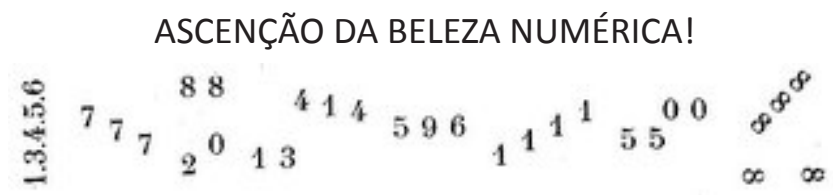

Dessa maneira, o segundo fragmento do poema contém dois aspetos típicos de outra escola artística, o futurismo: a entrega à natureza ondulatória dos sons e a atração pelos números. O primeiro aspeto lembra a veneração dos futuristas

o soneto Apoteose (junho de 1914). 4. Sá-Carneiro sempre assinava suas obras, escrevendo a data e o lugar. Em Manucure, só há uma assinatura. 5. A palavra "APOTEOSE" foi precedida de um ponto final - detalhe importante para o conjunto da obra (o ponto final designa o fim da oração, e não o título). Assim, para evitar dúvidas de interpretação, Fernando Cabral Martins recomenda colocar "APOTEOSE" no fim da página (SÁ-CARNEIRO, 2005, p. 256). 
às conquistas tecnológicas da modernidade; o segundo, a admiração por diferentes caracteres, em sua beleza e energia particulares. A propósito, no Manifesto técnico da literatura futurista (1912), Marinetti, como se sabe, proclama a "destruição da sintaxe". Para mostrar o movimento da frase e indicar sua entonação, ele sugere o uso de sinais matemáticos $(+-x:=\langle>)$ junto com sinais musicais.

Com efeito, nos versos seguintes Sá-Carneiro usa abertamente os princípios do futurismo e introduz no poema diversos caracteres, passando a ideia de uma "revolução tipográfica". (Este fragmento está separado por dois espaços em branco, procedimento típico de sua poética criando certa trégua, uma pausa, um pequeno descanso para os órgãos sensoriais, a começar para os olhos.)

Um estrangeiro sentado à mesa ao lado abre o jornal - e o poeta começa por distinguir certas letras, os títulos dos artigos, os logotipos dos anúncios, os variados caracteres, sinalizando a diversidade do mundo:

Eh-lá! grosso normando das manchettes em sensação!

Itálico afilado das crónicas diárias!

Corpo-12 romano, instalado, burguês e confortável!

Góticos, cursivos, rondas, inglesas, capitais!

Tipo miudinho dos pequenos anúncios!

Meu elzevir de curvas pederastas!...

E os ornamentos tipográficos, as vinhetas,

As grossas tarjas negras,

Os "puzzle" frívolos da pontuação,

Os asteriscos - e as aspas... os acentos...

Eh-lá! Eh-lá! Eh-lá!

[...]

Num rodopio de letras,

Todo o mundo repousa em suas mãos! (SÁ-CARNEIRO, 1996, p. 63).

Sá-Carneiro traz recortes dos principais jornais europeus em diferentes línguas, conservando, porém, seu aspecto original: 


\title{
O SÉCULO BERLINER TAGEBLATT
}

LE JOURNAL LA PRENSA

CORRIERE DELLA SERA THE TIMES

NOVOIÉ VREMIÁ; (ibidem, p.64)

intercala manchetes, algarismos, anúncios, nomes de firmas, bancos e mercadorias, destacando a ideia de uma "escrita em europeu", uma espécie de onomatopeia visual, um vozeado da modernidade:

\author{
“LE BOUILLON KUB PASTILLES VALDA \\ VIN DÉSILES \\ B E LLE J A R D I N I É RE \\ FONSECAS, HUNTLEY \& PALMERS "RODDY" \\ SANTOS \& VIANNA \\ Joseph Paquin, Bertholle \& C.ie \\ LES PARFUMS DE COTY \\ SOCIÉTÉ GÉNÉRALE \\ CRÉDIT LYONNAIS \\ BOOTH LINE NORDDEUTSCHER LLOYD \\ COMPAGNIE INTERNATIONALE DES WAGONS LITS \\ ET DES GRANDS EXPRESS EUROPÉENS (ibidem, p.65)
}

O autor de Manucure estava afinado com as tendências futuristas de Marinetti, citando-as e adaptando-as: "Ó estética futurista - up-to-date das marcas comerciais...", "Ascensão da Beleza Numérica!" ou "Palavras em liberdade, sons sem fios" (ibidem, p. 65).

O texto do poema pode ser interpretado pelo ponto de vista da realização do princípio das "palavras em liberdade": a abundância das reticências, as orações nominativas, as metonímias de objetos ou fenômenos. Um exemplo representativo encontra-se nos seguintes versos: "É no ar que ondeia tudo! É lá que tudo existe!..." (ibidem, p. 60).

Representado graficamente em forma de onda, estes versos expressam tanto sua realização visual quanto o princípio das "palavras em liberdade", transgredindo as normas de composição do texto escrito. No fim do poema, é possível 
"ouvir" a finíssima onomatopeia futurista: "ZING-TANG... ZING-TANG..." (ibidem, p. 68), que se corresponde com o pseudônimo de Marinetti Zang-tumb-tuuum. Dessa maneira, em Manucure, distinguem-se claramente dois novos e "agudos" estilos da primeira década do século XX - o cubismo e o futurismo, que, entretanto, não se contradizem: o poeta mostra como as estéticas futurista e cubista são complementares na tarefa de desvelar a Beleza do mundo.

No entanto, os ambiciosos intentos criativos dos poetas e pintores da geração Orpheu estavam além de uma simples adaptação dos estilos em voga. Em busca de uma renovação da poesia, Fernando Pessoa, com a participação de seu grande amigo Mário de Sá-Carneiro, criou o sistema de três estilos integrantes, alargando a já complicada paleta dos "ismos" vanguardistas. Em 1914 Pessoa escreveu a série dos poemas "Pauis...", e os princípios poéticos encontrados aqui receberam de seus amigos e adeptos o nome de paulismo. Logo depois surgiram o interseccionismo e o sensacionismo.

Se o paulismo, segundo Pessoa, caracteriza-se por expressões lineares de certas ideias num texto-colagem, o interseccionismo leva a uma escritura na qual certas imagens se entrelaçam não linearmente (isto é, não sucessivamente) ou de forma "poligonal", como dizia o próprio Pessoa, tentando captar o dinamismo da época. Assim, o objeto, como um fenômeno, só existe em movimento, que, em geral, é semelhante ao fluir da consciência.

Para se revelar a essência do objeto na poesia, este deve ser representado de forma complexa, em seus diferentes aspetos temporais e espaciais - a fantasia e a realidade têm de encontrar na consciência pontos de intersecção, assim como é necessário entrar em contato com diversas camadas de tempo. Pessoa explica:

Assim, cada sensação é um cubo, que se pode considerar pousado sobre o lado que representa $F$, e tendo voltado para cima o lado que representa $A$. Os outros lados são, evidentemente, B, C, D e E. Ora, este cubo pode ser observado [de fora] de três modos:

de um lado apenas, de forma que nenhum dos outros seja visível; com um lado de um quadrado mantido paralelo em relação aos olhos, de modo que se vejam dois lados do cubo; com um vértice mantido diante dos olhos, de modo que se vejam três lados. 
De ponto de vista objectivo [do interior], o Cubo da Sensação é constituído por: ideias = linhas, imagens (internas) $=$ planos, imagens de objectos = sólidos (apud MORNA, 1987, p. 25).

Foram expostas as possíveis disposições espaciais do objeto e do sujeito, do fenômeno apreendido e do observador. No primeiro caso, o observador pode captar apenas certas facetas do fenômeno, enquanto os seguintes dão a possibilidade ampliada de sentir a interação de elementos heterogêneos. Pode-se concluir que o primeiro exemplo do esquema deve corresponder ao paulismo; o segundo, ao interseccionismo.

Segundo Fernando Pessoa, a visão interseccionista do mundo ultrapassa os limites do cubismo e do futurismo. Enquanto o cubismo, em geral, marca os valores plásticos (a representação dos planos define seu modo de pintar) e o futurismo baseia-se principalmente no componente semântico (voltado para o futuro), o interseccionismo sintetiza a interação das imagens, determinando-a como seu princípio básico.

Sá-Carneiro recebia de bom grado as ideias de seus contemporâneos e incorporava-as admiravelmente a seu trabalho. A pluralidade de estilos em $\mathrm{Ma}$ nucure, usados de maneira intencional e ao mesmo tempo pessoal, expressos de forma evidente, devem ser compreendidos como o próprio estilo do poema: "Sim! - meus olhos futuristas, meus olhos cubistas, meus olhos interseccionistas..." (SÁ-CARNEIRO, 1996, p. 59).

O olhar interseccionista em Manucure revela-se nas diversas combinações de um mesmo objeto e na apreensão do mundo através delas. O autor distingue três faces de um único objeto, isto é, da Beleza: a beleza das impressões visuais, do espaço repleto de figuras geométricas (combinações variadas de objetos mesas, cadeiras, bancos, caixotes); a beleza dos elementos sonoros difundidos no ar (fragmentos de conversas telefônicas, onomatopeias, gritos, o ruído da bandeja que caiu, ondas acústicas); e a beleza tipográfica dos jornais (letras, algarismos, sinais de pontuação, anúncios) e dos diversos cartazes e placas do espaço urbano da época.

As faces do objeto ligam-se de forma variada e interagem umas com as outras ao longo do texto, levando o leitor às diversas formas da Beleza ansiada pelo poeta. Alguns exemplos de combinações de sons e letras (em forma de algarismos): 
Pede uma voz um número ao telephone:

Norte $-2,0,5,7 \ldots$

E no Ar eis que se cravam moldes de algarismos... (ibidem, p. 60)

E de combinações de espaços e sons:

Um novo turbilhão de ondas prateadas

Se alarga em ecos circulares, rútilos, farfalhantes

Como água fria a salpicar e a refrescar o ambiente... (ibidem, p. 61)

Combinações de palavras orais e escritas também definem uma interação interseccionista:

(Hip! Hip-lá! nova simpatia onomatopaica,

Recendente da beleza alfabética pura:

Uu-um... kess-kress... vliim... tlin... blong... flong... flak...

Pâ-am-pam! Pam... pam... pum... pum... Hurrah!) (ibidem, p. 64)

Já um exemplo mais requintado de sinestesia interseccionista se acha na combinação do tato ("balcões de zinco") e paladar (nomes de cocktails):

Antes de me erguer lembra-me ainda,

A maravilha parisiense dos balcões de zinco,

Nos bares... não sei porquê...

-Un vermouth-cassis... Un Pernod à l'eau...

Un amer-citron... Une grenadine... (ibidem, p. 66)

O ápice do interseccionismo, no entanto, revela-se no poema com a "ondulação" conjunta de letras e planos:

Tudo isto, porém, tudo isto, de novo eu refiro ao $\mathrm{Ar}$

Pois toda esta Beleza ondeia lá também:

Números e letras, firmas e cartazes -

Altos-relevos, ornamentação!... (ibidem, p. 66) 
No fim do poema, o autor apresenta sua fórmula "matemático-humanitária", o ponto culminante da arte vanguardista preconizada por ele:

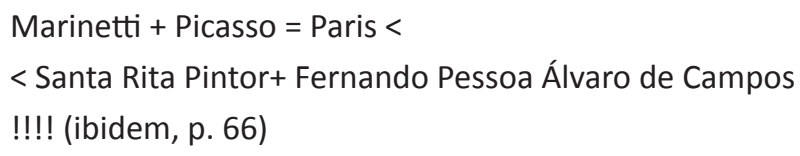

Essa fórmula resume as últimas tendências das vanguardas e, além disso, cria uma hierarquia entre os elementos. Conforme o poeta, a soma de Marinetti, o arauto do futurismo, e Picasso, o líder incondicional do cubismo, equivale à boémia de Paris - a capital vanguardista por excelência. Mas, mesmo juntos, eles não se igualam à união do talento de Santa-Rita Pintor, das teorias precisas de Fernando Pessoa e das experimentações poéticas de Álvaro de Campos, os representantes do interseccionismo, fruto da genialidade portuguesa, sublinhado por quatro pontos de exclamação.

Mário de Sá-Carneiro, radicado em Paris a partir de 1912, soube mais do que compreender as nuances da arte de sua época: foi um dos partícipes desse movimento, e Manucure é a prova cabal disso.

\section{Referências}

D’ALGE, Carlos. Experiência futurista e a geração de "Orpheu". Lisboa: Centro de Arte Moderna José de Azeredo Perdigão, Fundação Calouste Gulbenkian, 2006.

DIAS, Marina Tavares. Mário de Sá-Carneiro: . fotobiografia. Lisboa: Quimera Editores, 1988.

Dicionário Houaiss da Língua Portuguesa. CD-ROM. Serial - DHS - 21571925.

DINE, Madalena Jorge; FERNANDES, Marina Sequeira. Para uma leitura da Poesia Modernista: Mário de Sá-Carneiro e José de Almada Negreiros. Lisboa: Editorial Presença, 2000.

JÚDICE, Nuno. A era do "Orpheu". Lisboa: Editorial Teorema, 1986.

LEMAIRE, Gerard-Georges. Les Cafés Littéraire : vies, morts et miracles. Paris: Editions de la Différence, 1997.

MARTINS, Fernando Cabral. O Modernismo em Mário de Sá-Carneiro. Lisboa: Imprensa Universitária, Editorial Estampa, 1994.

MORNA, Fátima Freitas. A poesia de Orpheu. Lisboa: Editorial Comunicação, 1987. 
SÁ-CARNEIRO, Mário de. Poemas completos. Lisboa: Assírio \& Alvim, 1996.

SÁ-CARNEIRO, Mário de. Poemas completos. Lisboa: Assírio \& Alvim, 2005.

SÁ-CARNEIRO, Mário de. Correspondência com Fernando Pessoa. Lisboa: V I., V. II., 2003. TELES, Gilberto Mendonça. Vanguarda europeia e modernismo brasileiro. Rio de Janeiro: Record, 1987.

Submetido em 05-01-16

Aprovado para publicação em 24-06-16 